\title{
Strategic e-Business Decision Analysis Using the Analytic Network Process
}

\author{
Mahesh S. Raisinghani, Laura Meade, and Lawrence L. Schkade
}

\begin{abstract}
The rapid global deployment of electronic business (e-business) and information systems has required managers to make decisions that seek to balance technical factors with strategic business goals. This research utilizes the analytic network process (ANP) to provide insight into optimum-seeking decision processes by managers, as investments are made to utilize e-commerce technologies. The nonlinear network approach of ANP was used to study the "systems with feedback" where the e-commerce strategy may both dominate and be dominated, directly and indirectly, by the business-level strategy. This study analyzes e-business decisions in organizations, based on management heuristics and perceptions of expected contributions of e-commerce strategies, as well as the business-level strategies. The ANP research methodology process is employed since it is well suited for the study of a multi-attribute decision problem to explore qualitative and quantitative preferences of top managers in independent, nondiversified firms involved in e-business. ANP is used to model decision complexities involved in integrating e-commerce innovation into the overall strategic planning of firms. Optimal e-business strategies are chosen by using systems-with-feedback, where interdependencies between four virtual e-commerce domains and two generic business level strategies are explored. This study obtained significant results and identified several important avenues for further research. Implications for theory and research are discussed.
\end{abstract}

Index Terms-Analytic network process (ANP), decision support system, electronic business (e-business), e-commerce models, e-strategy, qualitative and quantitative decision making, strategic decisions.

\section{INTRODUCTION}

$\mathbf{T}$ HE RAPID deployment of electronic business (e-business) is an economically significant issue for today's business. An e-business solution is defined as: 1) improving business processes using Internet technologies; 2) leveraging the Web to bring together customers, vendors, suppliers, and employees in ways never before possible; and 3) Web-enabling a business to sell products, improve customer service, and obtain maximum results from limited resources [49]. Brynjolfsson [5], [6] writes that there is a need for new metrics that go beyond the traditional industrial-age measures that focus primarily on cost analysis and savings, because of the difficulty of measuring the

Manuscript received May 1, 2004; revised August 1, 2005, March 1, 2006, and August 1, 2006. Review of this manuscript was arranged by Department Editor A. Chakrabarti.

M. S. Raisinghani is with the School of Management, Texas Woman's University, Denton, TX 76204 USA

L. Meade is with Texas Christian University, Fort Worth, TX 76109 USA (e-mail:1.meade@tcu.edu).

L. L. Schkade is with the Department of Information Systems and Management Sciences, University of Texas at Arlington, Arlington, TX 76019-0018 USA.

Digital Object Identifier 10.1109/TEM.2007.906857 true economic benefits of information technology (IT) and determining the accurate accounting of IT returns. This research addresses the measurement of linkages between strategic business goals and e-commerce strategy, chosen by managers, for e-business decisions using the analytic network process (ANP).

An ANP was selected for three reasons. First, ANP is a system for the analysis, synthesis, and justification of complex decisions such as those characterized by interdependencies between the e-commerce-level and business-level strategies in this study. Second, ANP has the capability to model nonlinear relationships between the elements being considered in a decision, such as feedback and dependencies among problem elements. Third, ANP was chosen from a variety of multiple criteria decision making methods due to its suitability for group decisionmaking, since it allows one to focus on objectives rather than on alternatives, and offers numerous benefits as a synthesizing mechanism in group decisions [4], [10].

This research investigated the following two research questions.

1) Given the stage of e-commerce adoption by an organization when deciding on an optimal e-business strategy, is differentiation considered to be a more important strategy than cost leadership or vice versa?

2) Given the stage of e-commerce adoption by an organization, with respect to the differentiation strategy, are innovation-based, marketing-based, and response-time based differentiation strategies equally important in making optimal e-business decisions?

ANP provides a method for conceptualizing and identifying a combination of qualitative and quantitative variables for evaluating e-business strategies comprising e-commerce level and business-level strategies. An integrated matrix is provided for evaluating various qualitative and quantitative criteria of ecommerce strategy and business strategy, e.g., speed to market a product/service, and task-technology fit. Linkage matrices are effective tools for depicting relationships between e-commerce strategy and business strategy. This linking process can stimulate management discussion of the value of strategic alignment between e-commerce and business strategy for e-business, by considering tangible (e.g., cost analysis and savings) and intangible (e.g., customer satisfaction) benefits and the cause-andeffect relationship between IT and the achievement of strategic business goals. ANP assigns weights to metrics in the model to enhance the assessment of the relative importance of key factors involved in the decision. An additional in-depth analysis of these factors, based on data obtained from a survey questionnaire and structured interviews, provides insight into multiattribute preference theory, as applied to the strategic evaluation of e-business 
decisions. The nonlinear network approach of ANP was used to study the "systems with feedback," where the e-commerce strategy may both dominate and be dominated, directly and indirectly, by the business-level strategy.

\section{Synthesis OF BusinESS-LEVEL StRATEGY}

In conducting a meta-analysis of strategy research [22], [26], [30], [42], Miller [30] found four broad categories of variables or dimensions with which to classify business-level competitive strategies. These four dimensions of strategic content are differentiation, cost-leadership, focus, and asset parsimony/intensity. Differentiation seeks to create a product and/or service that is perceived by customers as unique (e.g., Cross Pen or Rolls Royce autos). Porter's strategy of cost leadership requires firms to become the lowest cost producers in an industry, and effort is devoted to cost control so that above-average returns can be obtained even with low prices (e.g., Southwest Airlines or Walmart).

The focus strategy refers to the variety of customers, their geographic range and the number of products [for example, $\mathrm{Mi}$ crosoft (MS) and its horizontal software applications targeted at the office applications market such as MS Office]. The focus strategy "rests on the premise that the firm is ... able to serve its narrow strategic target market more effectively or efficiently than competitors who are competing more broadly. As a result, the firm achieves either differentiation by meeting the needs of the particular target more effectively, lowering costs of serving this target, or both" [30]. Finally, asset parsimony refers to the scantiness of assets per unit output [22]. This approach is used by differentiators in organizations that must be flexible and responsive to market demands. In contrast, asset intensity is used by cost leaders operating in stable environments, since asset intensity can provide for greater efficiency. However, winners in the e-business arena such as eBay and CharlesSchwab (schwab.com) have widely varying balance sheets, overhead structures, cost of capital, incremental margins, and a premium price in the marketplace. In other words, winners compete from a radically different position of economic strength.

Porter [34] writes that the risks associated with differentiation are different from those of focus. Differentiation implies industry-wide competition, while focus concerns marketsegment competition. However, since e-business efforts may span more than one segment, the data in this study was collected from a variety of industries.

In the context of e-business, asset parsimony/intensity is not an appropriate strategy, since hardware/software assets are relatively inexpensive in comparison to other assets such as building, plant, and automobiles. Moreover, network-centric computing and client-server computing have driven hardware acquisition costs downward substantially in comparison to legacy-based systems. On the other hand, it could be argued that any service firm/s (e.g., government agency, banking) that only exist as an e-business may have most of their accounting assets in hardware and/or software. However, in view of model manageability, data collection, brevity, and simplification considerations, focus and asset parsimony/intensity were not included as independent
TABLE I

REPRESENTATIVE STRATEGIC VARIABLES Within EACH DIMENSION

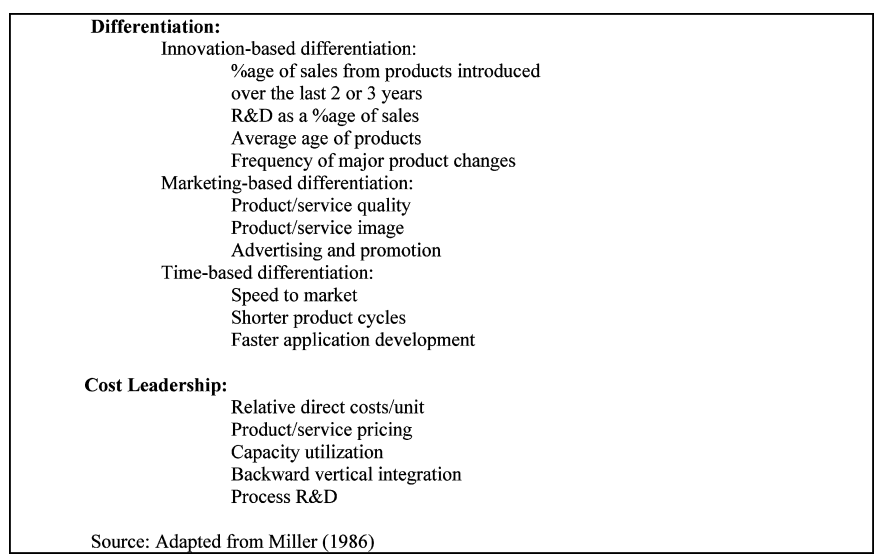

strategies in our analytical model, but they could be included in a more comprehensive ANP model, because ANP is flexible and expandable.

Dimensions of the differentiation and cost leadership strategies included in this study were selected based on the assumption of correlated elements or variables. Published empirical taxonomies, including Hambrick [16], [17], Miller and Friesen [30], MacMillan and Hambrick [25], Dess and Davis [9], and Dess and Miller [10], show that many of the variables and dimensions (Table I) are correlated. These strategic variables are used in the first step of ANP model construction and problem structuring (discussed in the overview of the research framework that follows).

Since comparisons of multiple pairs of items are required by ANP modeling, the relative importance of two generic businesslevel strategies (i.e., cost leadership and differentiation) and the three dimensions of differentiation (innovation, marketing, and response time) are explored in this study.

\section{DECISION SUPPORT USING ANP}

ANP, a generalization of the analytic hierarchy process (AHP), is a decision analysis methodology that employs a set of axioms to develop a hierarchy of attribute values, based on the relative values obtained from pair-wise comparisons of attributes [23], [43]. The advantage of ANP over AHP for multicriteria decision making is the allowance for interdependence between levels. Concepts of systems with feedback are employed extended to demonstrate how to study inner and outer dependence with feedback. Inner dependence is the interdependence within a component in combination with feedback between components, and outer dependence is defined as the dependence between components in processes with feedback capabilities. For example, when deciding how closely or loosely to integrate the e-business initiatives of an organization that has traditional operations, a decision maker can determine the optimal e-business strategy by choosing between various e-business business model alternatives [i.e., such as a spin-off (e.g., Barnesandnoble.com), a strategic partnership (e.g., Rite Aid and Drugstore.com), a joint venture (e.g., KBkids.com), or an in-house division (e.g., OfficeDepot.com)]. This process can be 


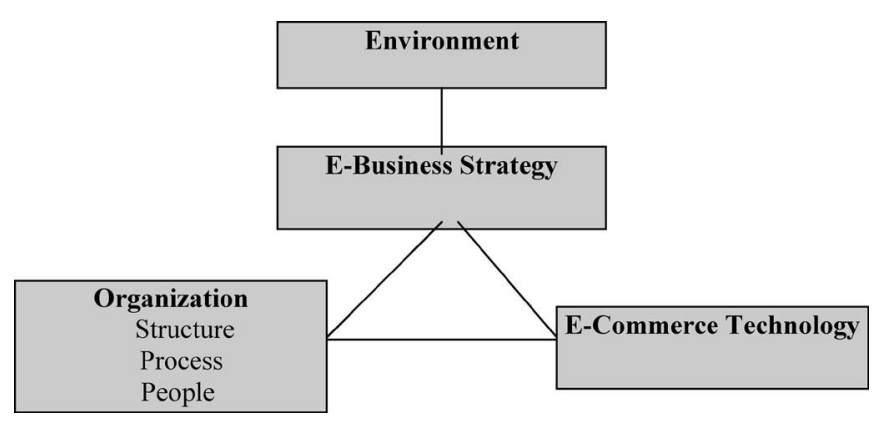

Fig. 1. e-Business task-technology fit.

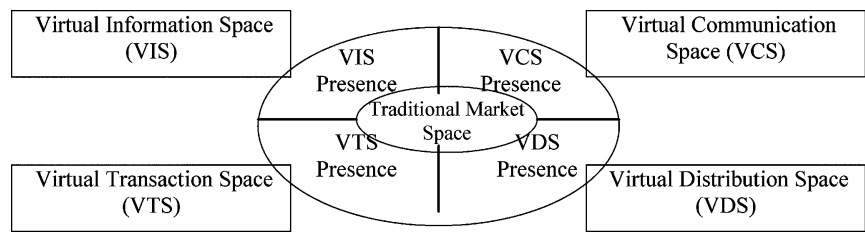

Fig. 2. Four domains of e-commerce expansion.

illustrated by modeling the interdependence and feedback between the e-commerce strategy and the business-level strategy that results from the strategic alignment needed between business and technology decisions. The issues of alignment relevant to e-business (illustrated in Fig. 1) are between technology and strategy.

Balance between strategy and technology is achieved when an organization uses technology to differentiate its products and/or services, as well as provide a high level of integrated service to customers. Alignment between technology and organizational processes requires the redefinition of processes affected by ebusiness. This alignment could be achieved through the use of technology to redesign the process to reduce cost and minimize errors associated with the process, while also increasing the level of service.

\section{RESEARCH FRAMEWORK}

A systematic framework for the identification and classification of e-commerce strategy using Internet information, communication, distribution, or transaction channels is illustrated in Fig. 2 [1], [2]. These relationships correlate closely with the diffusion of e-commerce in terms of waves/phases.

The virtual information space (VIS) presents new channels for economic agents to display and access-related company product and services information (e.g., marketing and advertising). The virtual communication space (VCS) includes strategies aimed at monitoring and influencing business-related communications between economic agents operating on the Internet (e.g., negotiations between potential and existing customers partners, government agencies, and competitors). The virtual distribution space (VDS) provides new channels for economic agents to distribute products and services (e.g., software). Lastly, the virtual transaction space (VTS) provides strategies for economic agents with which to initiate and execute businessto-business (B2B) or business-to-customer (B2C) transactions, such as orders and payments.

\section{A. ANP Model}

Saaty [43], [44] developed the ANP for multiattribute decision structuring and decision analysis. ANP allows a set of complex issues (factors) that have an impact on an overall objective to be compared with the importance of each issue (factor) relative to its impact on the solution of the problem. ANP models a decision-making framework that assumes a unidirectional hierarchical relationship among decision levels. ANP has the following basic steps.

1) Development of a decision hierarchy. The top element of the hierarchy (apex) is the overall goal for the decision model. (In this case, "Determine Optimal E-business Strategy.")

2) The hierarchy decomposes to a more specific attribute until a level of manageable decision criteria is met. The hierarchy is a type of system where one group of entities influences another set of entities.

3) Pairwise comparisons are conducted to estimate the relative importance weights (or allocations) of the various elements on each level of the hierarchy.

4) The weights obtained are integrated to develop an overall ranking of decision alternatives.

5) The interdependencies in the model are resolved by a supermatrix approach. (The interdependency in this model is between the four domains for E-commerce strategy development and the attributes of business-level strategy/strategic metrics.)

Fig. 3 presents the ANP model used for determining the optimal e-business strategy.

\section{Research Methodology}

\section{A. Nature of the Study}

This research uses the ANP methodology to describe and measure (with the intent of refining the traditional metrics used for decision making) the analogical reasoning involved in making optimal e-business decisions. Data collection was conducted as a live, Web-based survey for respondents with Internet access. In addition, offline, hard copy questionnaires were used by respondents who either did not have access to the Internet or preferred to complete the survey form offline, utilizing a multiitem survey instrument for data and subjective knowledge collection.

Exploratory and descriptive surveys can help to identify concepts and the basis for measurement and are very appropriate for the early stages of the research [14]. For these reasons, this paper employed a survey methodology for data collection. The methodology employed in this paper is based on the general system theory and the contingency theory. General system theory (GST) emphasizes the importance of holism and views an organization as a goal-seeking, adaptive open system. Contingency theories have been widely used in research on organization behavior, design, performance, planning, and management strategy. Contingency theory views an organizational outcome as the result of a fit or match between two or more factors [48]. The underlying premise is that there is no general solution that 


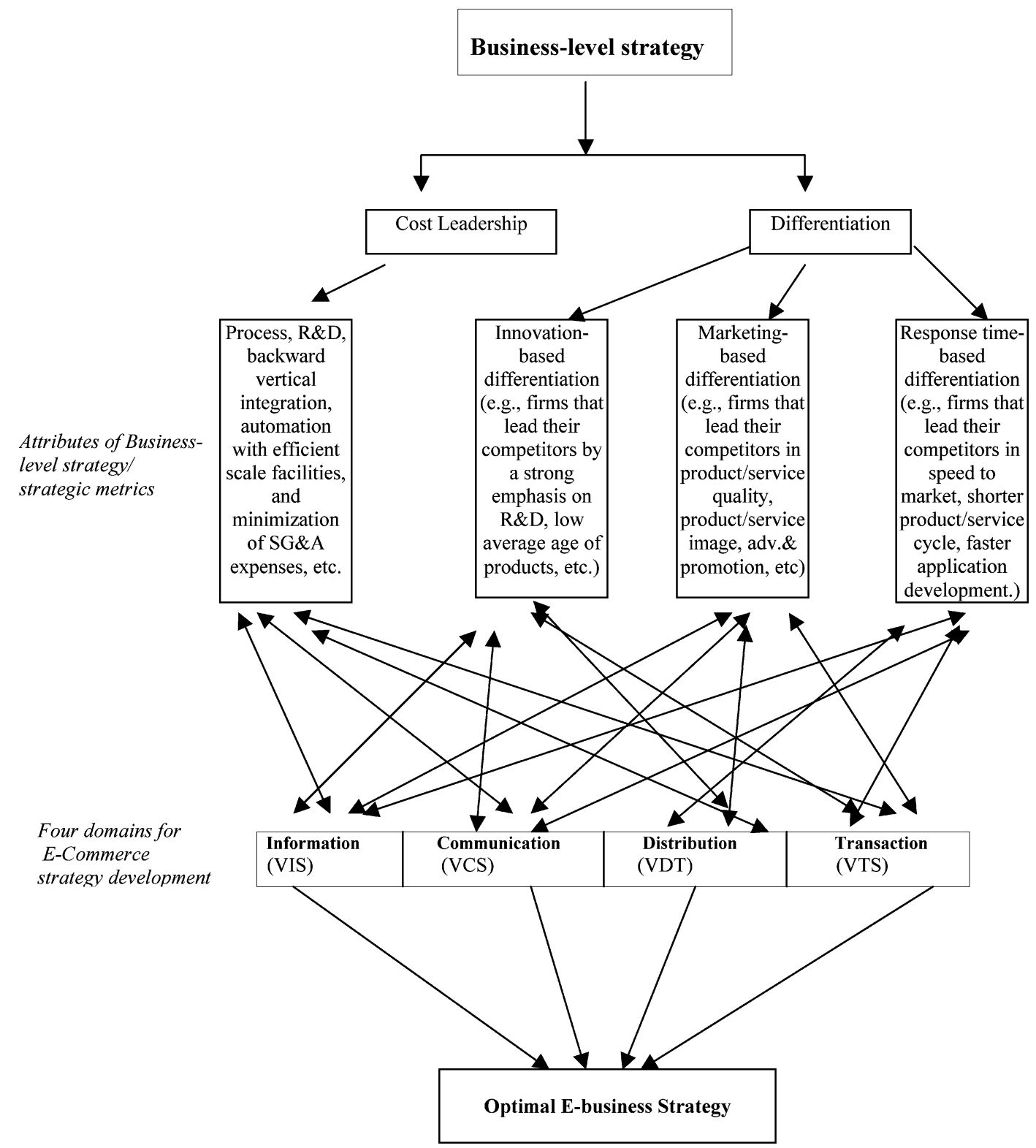

Fig. 3. ANP model for determining the optimal e-business strategy.

is appropriate for all organizations. GST is applied in this paper by having a systemic decision process for selecting the optimal e-business strategy that it considers the capabilities and contributions made by each alternative to the overall vision and mission of an organization. Contingency theory is applied in this study by allowing flexibility in reaching judgments in response to the external and internal environmental factors encountered by the decision maker.

\section{B. Research Design}

A cross-sectional survey research design was used in this study. Since previous studies have shown that information systems (IS) and business executives do not necessarily think alike [39], both technical and executive groups (i.e., Information Systems Managers, Chief Information Officers (CIO's), Web
Administrators as well as Chief Executive Officers (CEOs), Chief Financial officers (CFOs), and Vice Presidents) were sampled in this research. Linkages between business and ecommerce strategy (as illustrated in Fig. 3 by the two-way arrows) tie each of the four virtual domains of e-commerce strategy to business-level strategies. These arrows depict the pairings of four virtual domains of e-commerce technology with each of the subcategories of the business strategies at the corporate level. This focus is necessary, since business units in different organizations can exhibit varying levels of linkages, making an overall single measure for an organization inappropriate [39], [40].

Organizations actively involved in e-business were selected randomly from the Internet Commerce Directory and the Dallas/ Fort Worth E-Commerce Forum's member directory. The following criteria were employed in selecting the sample. 
1) A firm must be an independent business (with or without multiple business units), rather than a subsidiary, a division of another firm, or a unit of a conglomerate. This criterion ensures that the top management team members' decision rules and the firm's strategy and structure are not influenced by those of a parent firm, thus assuming firm autonomy [7].

2) A firm must be limited to a single industry [40], as indicated by one four-digit standard industrial classification (SIC) code, which helps to ensure that the responses of executives focus only on the environment and strategy of the primary business, rather than the potential multiple strategies and environments associated with diversified firms. The closest match was found in the Dun's Regional Business Directory, with SIC code 7379-99 for firms offering computer-related services and SIC code 7375-02 for firms offering information retrieval services. Thus, the second criterion had to be relaxed in some cases to ensure adequate sample size, but only where it was clear that the firm participated in two four-digit SICs considered to be in the same industry.

3) Firms in the sample must apply e-commerce technology within one or more functional business area(s) (as opposed to being in the planning stage of e-commerce technology adoption), including (but not limited to) customer service and support, sales and marketing, administration, distribution, and research and development.

\section{Data Collection Procedures}

A participation solicitation letter providing a general description of the nature and importance of the study and the Universal Resource Locator (URL) for the website that hosts the live Webbased survey was e-mailed to the attention of a member of the Top Management Team (TMT) (i.e., CEO, CFO, VP) of companies that met the aforementioned three criteria. Individuals were selected based on the TMT member listed in the Internet Commerce directory and D/FW E-commerce Forum Directory. This TMT member was asked to enlist participation of other TMT members and technical managers in their organization, such as web administrators, CIO's, and IS managers. The letter asked that individuals responsible for making strategic decisions pertaining to e-business either visit the Web site to complete the survey, respond to an e-mail that included the questionnaire, or ask for a hardcopy of the survey with which to respond. Confidentiality of individual responses was assured and maintained, and an executive summary of study was provided to the respondents.

In the survey that was administered in the late 1990s, respondents were asked to make pairwise comparison of alternatives with regard to the parent node/control variable, one level above the level in the hierarchy being considered. Firm-specific questions were designed to elicit executive perceptions of each investment in e-commerce technology by the firm. Follow-up phone calls and e-mails (with URL address reminders and/or questionnaires by e-mail) were necessary to increase the number of completed questionnaires.

\section{Instrument Validation}

To ensure consistency and reliability, standard definitions of all business/technical terms (e.g., VIS, VCS) used in the survey were provided prior to each instance that referred to the term in the questionnaire on the World Wide Web (WWW), as well as on every page of the hard copy format. To confirm clarity and appropriateness of the ANP tool and the questionnaire, a pilot study was conducted using one firm that had initiated, adopted, and implemented e-commerce for its daily operations, and a group of advanced MBA students. The pilot study responses were not included in the final study. Minor clarifications in the survey were made based on pilot study results. Internal consistency and measurement reliability of the items were verified by computing the Cronbach's alpha [32]. Items with low interitem correlations were deleted from the study.

\section{Data ANALYSis}

The overall objective of the ANP model, presented in Fig. 3, is to determine an optimal e-business strategy. This application addresses two specific questions: 1) Given the stage of e-commerce adoption by an organization, when deciding on an optimal e-business strategy, is differentiation considered to be a more important strategy than cost leadership or vice versa? 2) Given the stage of e-commerce adoption by an organization, with respect to the differentiation strategy, are innovationbased, marketing-based, and response-time-based differentiation strategies equally important in making optimal e-business decisions? The ANP model, presented in Fig. 3, is illustrated by the following three steps that depict its theoretical framework [26], [27], [44] and provide an integrated perspective of the data analysis needed in this decision process.

Step 1: Matrices of paired comparisons of interdependent component levels. Once the ANP model is specified, a decision maker compares two components at a time sequentially with respect to an upper level control criterion. For example, a respondent is asked to choose one of two items in a pair as being more important, e.g., either cost leadership strategy or differentiation strategy is selected as being relatively more important with respect to the optimal e-business strategy. These comparisons indicate the extent of impact that the two generic business level strategies being compared have on each domain of e-commerce expansion in the e-commerce strategy. Repeated paired choices enable the determination of the optimal strategic alignment of business strategy with the virtual dimensions of e-commerce technologies. Paired comparison matrices for the four virtual domains provide a summary basis for deciding on e-commerce expansion. A nine-point ratio measurement scale, developed by Saaty [44], was used to make the comparisons because, in many cases, an ordinal/verbal scale, rather than a linear interval/quantitative scale, is used to make comparisons and is incorporated as a ratio scale.

As ANP was employed to capture choices, alternatives being considered were compared with respect to the sub criteria/criteria included in the lowest level of the hierarchy. Global weights were determined for each of the alternatives within each subcriterion. The global weights, summed over the subcriteria, 
TABLE II

BUSINESS STRATEGY PAIRWISE COMPARISON MATRIX

\begin{tabular}{|l|l|l|l|l|}
\hline $\begin{array}{l}\text { Virtual } \\
\text { Information } \\
\text { Space (VIS) }\end{array}$ & $\begin{array}{l}\text { Cost } \\
\text { Leadership }\end{array}$ & Differentiation & $\begin{array}{l}\text { Geometric } \\
\text { mean (gmean) }\end{array}$ & $\begin{array}{l}\text { Eigenvector } \\
(\mathrm{eVector})\end{array}$ \\
\hline Cost Leadership & 1 & 4.941 & 2.223 & 0.832 \\
\hline Differentiation & 0.202 & 1 & 0.450 & 0.168 \\
\hline & & Totals & 2.673 & 1.000 \\
\hline
\end{tabular}

were then used to determine the relative ranking of alternatives. The alternative with the highest global sum of weights is the most desirable alternative. In focusing on decisions, tactical as well as strategic tradeoffs are made among multiple competing objectives. This basic approach is based on preference/ utility theory and includes use of subjective probabilities [22], [36], [38].

In scoring a paired choice in ANP, a reciprocal value is assigned automatically to the reverse comparison within the matrix. The local priority vector $\mathbf{w}$ (defined as the eVector), which is the weighted average of each attribute, is computed as the unique solution to

$$
A w=\lambda_{\max } W
$$

where $\lambda_{\max }$ is the largest eigenvalue of matrix $A$. Next, to aggregate over normalized columns, each element in a column is divided by the sum of the column elements. After summing the elements in each row of the resultant matrix, each quotient is divided by the number of elements $n$ in each respective row. Mathematically, the relationship is expressed by

$$
w_{i}=\frac{\sum_{i=1}^{I}\left\{a_{\mathrm{ij}} / \sum_{j=1}^{J} a_{\mathrm{ij}}\right\}}{J}
$$

where

$w_{i} \quad$ weighted priority for component $i$;

$J$ index number of columns (components);

$I$ index number of rows (components).

Table II illustrates the business strategy pairwise comparison matrix for the VIS. With respect to the e-commerce strategy development, how much more important is business-level strategy factor in row $I$ as compared to another business-level strategy factor in column $J$ ? (1/9 means that $I$ is very less important than $J ; 9$ indicates $I$ is very much more important than $J ; 1$ means equal.)

Decision makers were asked, "In terms of Virtual Information Space, how much more important is cost leadership than differentiation?" Table II shows that cost leadership is viewed as being more important, as reflected by a weighting of 4.941 (the average of all the respondents) versus 0.202 , and weighted priorities for this matrix of normalized weightings are shown in the column labeled eigenvectors (eVector). Note that since the values are normalized, the sum of the eVector column is equal to one.

The procedure detailed before was repeated to develop a matrix for the remaining three virtual spaces, VCS, VDS, and VTS, wherein the eVector of local priority weights for the relative impact of the e-commerce expansion strategy are calculated for a business strategy. The results form matrices $\mathbf{A}$ and $\mathbf{B}$ that are re-
TABLE III

MATRIX A OF WeIGHTED PRIORITIES OF FOUR DOMAINS OF e-COMMERCE STRATEGY

\begin{tabular}{|l|l|l|l|l|}
\hline & VIS & VCS & VDS & VTS \\
\hline Differentiation & 0.168 & 0.159 & 0.163 & 0.183 \\
\hline $\begin{array}{l}\text { Low-Cost } \\
\text { Leadership }\end{array}$ & 0.832 & 0.841 & 0.837 & 0.817 \\
\hline
\end{tabular}

quired for each level of the hierarchy considered in relation to the parent/control node (i.e., innovation-based/marketingbased/response-time-based differentiation considered with respect to differentiation strategy). Matrix A (Table III) summarizes the weighted priorities of the four virtual domains of e-commerce technology for e-commerce strategy. Table III is constructed for VIS, VCS, VDS, and VTS, respectively, and the weighted priorities for each of the four strategy relationship matrices. The geometric mean is used to average a sample multiindustry and multifunctional group preference, without obscuring the differences of individual opinions. Table III also indicates that a low-cost leadership business level strategy is preferred over the differentiation strategy in all four domains of e-commerce strategy.

Table IV shows matrix B that summarizes average pairwise comparisons between the four domains of the e-commerce strategy in terms of the business-level strategies of cost leadership and differentiation.

Step 2: Formulation of the supermatrix. The supermatrix, shown in Fig. 4, compiles the submatrices of sets of relationships between two levels (i.e., the four domains of the ecommerce strategy and the business-level strategy) in the ANP model illustrated in Fig. 3. Fig. 4 illustrates the network model of supermatrix relationships. This supermatrix enables the resolution of the effects of interdependence that exist between the elements of the system. Interdependence, shown in Fig. 3, is between the four domains of the e-commerce strategy and the business level strategy, as indicated by the two-way arrows. Resolution of the effects of interdependence that exist between the elements of the system is enabled by considering: 1) independence from succeeding components; 2) interdependence among components; and 3) interdependence between levels of components [44]. Since the interdependencies of a level of components on itself (represented by matrices $\mathbf{C}$ and $\mathbf{D}$ in Fig. 4) are not considered to be significant, a value of zero is assigned.

The next step with the supermatrix evaluation is to determine the final relative importance of weights of each of the alternatives. To complete this step and help guarantee convergence, the columns of the supermatrix must be "column stochastic." That is, the weights of each column for the supermatrix need to sum to 1 . This was completed in the calculation of the eVector in each pairwise comparison matrix.

The $6 \times 6$ supermatrix $\mathbf{M}$ for the optimal technical strategic mix problem, shown in Table $\mathrm{V}$, is formed by combining the two compiled matrices $\mathbf{A}$ and $\mathbf{B}$.

According to Saaty [44], [45], to reach convergence of the interdependent relationships between the two levels being compared, it is necessary to raise the supermatrix to the power $2 k+1$, where $k$ is an arbitrary large number. These "long-term" 
TABLE IV

MATRIX B OF RESPONDENT WEIGHTINGS

\begin{tabular}{|c|c|c|c|c|c|c|}
\hline $\begin{array}{l}\text { Low-Cost } \\
\text { Leadership }\end{array}$ & VIS & VCS & VDS & VTS & $\begin{array}{l}\text { Geometric } \\
\text { mean (gmean) }\end{array}$ & $\begin{array}{l}\text { Eigenvector } \\
\text { (eVector) }\end{array}$ \\
\hline VIS & 1.000 & 4.386 & 4.587 & 5.464 & 3.238 & 0.563 \\
\hline VCS & 0.228 & 1.000 & 4.505 & 5.102 & 1.513 & 0.263 \\
\hline VDS & 0.218 & 0.222 & 1.000 & 5.155 & 0.707 & 0.123 \\
\hline \multirow[t]{2}{*}{ VTS } & 0.183 & 0.196 & 0.194 & 1.000 & 0.289 & 0.050 \\
\hline & & & & Totals & 5.747 & 1.000 \\
\hline Differentiation & VIS & VCS & VDS & VTS & gmean & eVector \\
\hline VIS & 1.000 & 4.219 & 4.926 & 4.695 & 3.143 & 0.554 \\
\hline VCS & 0.237 & 1.000 & 5.102 & 4.762 & 1.549 & 0.273 \\
\hline VDS & 0.203 & 0.196 & 1.000 & 5.102 & 0.671 & 0.118 \\
\hline \multirow[t]{2}{*}{ VTS } & 0.213 & 0.210 & 0.196 & 1.000 & 0.306 & 0.054 \\
\hline & & & & Totals & 5.669 & 1.000 \\
\hline
\end{tabular}
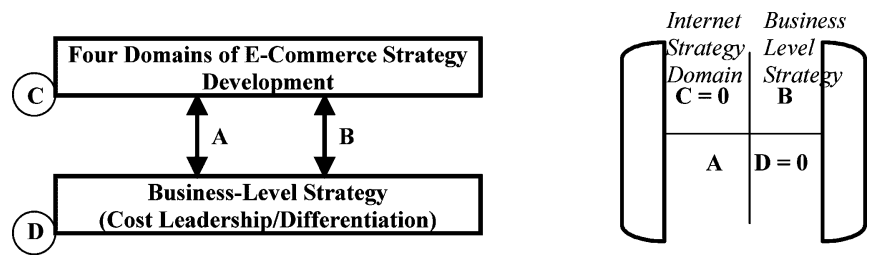

Fig. 4. Network and matrix model of supermatrix relationships.

TABLE V

SUPERMATRIX M FOR THE OPTIMAL e-COMMERCE STRATEGY INTERDEPENDENCIES BEFORE CONVERGENCE

\begin{tabular}{|l|l|l|l|l|l|l|}
\hline & VIS & VCS & VDS & VTS & Differentiation & $\begin{array}{l}\text { Low-Cost } \\
\text { Leadership }\end{array}$ \\
\hline VIS & 0 & 0 & 0 & 0 & 0.554 & 0.563 \\
\hline VCS & 0 & 0 & 0 & 0 & 0.273 & 0.263 \\
\hline VDS & 0 & 0 & 0 & 0 & 0.118 & 0.123 \\
\hline VTS & 0 & 0 & 0 & 0 & 0.054 & 0.05 \\
\hline Differentiation & 0.168 & 0.159 & 0.163 & 0.183 & 0 & 0 \\
\hline $\begin{array}{l}\text { Low-Cost } \\
\text { Leadership }\end{array}$ & 0.832 & 0.841 & 0.837 & 0.817 & 0 & 0 \\
\hline
\end{tabular}

TABLE VI

CONVERGED SUPERMATRIX FOR THE OPTIMAL e-COMMERCE STRATEGY INTERDEPENDENCIES

\begin{tabular}{|l|l|l|l|l|l|l|}
\hline & VIS & VCS & VDS & VTS & Differentiation & $\begin{array}{l}\text { Low-Cost } \\
\text { Leadership }\end{array}$ \\
\hline VIS & 0 & 0 & 0 & 0 & 0.561 & 0.561 \\
\hline VCS & 0 & 0 & 0 & 0 & 0.265 & 0.265 \\
\hline VDS & 0 & 0 & 0 & 0 & 0.122 & 0.122 \\
\hline VTS & 0 & 0 & 0 & 0 & 0.051 & 0.051 \\
\hline Differentiation & 0.165 & 0.165 & 0.165 & 0.165 & 0 & 0 \\
\hline $\begin{array}{l}\text { Low-Cost } \\
\text { Leadership }\end{array}$ & 0.831 & 0.831 & 0.831 & 0.831 & 0 & 0 \\
\hline
\end{tabular}

stable weighted values are used for further analysis. For convergence to a final set of weights, we raised the normalized (column stochastic) supermatrix to a large power until stabilization of the weights occurs. For our example, convergence occurred when the supermatrix was raised to the 32 nd power.

Table VI is the converged supermatrix for $k=32$.

Step 3: Selection of the Best Alternative. The "desirability index" for an alternative $i\left(D_{i}\right)$ determines the best alternative and is illustrated in Table VII. It is computed by

$$
D_{i}=\sum \sum W_{1} W_{2} W_{3}
$$

where

$W_{1}$ relative importance weight of the e-commerce strategy;

$W_{2}$ relative importance weight for business level strategy;

$W_{3}$ relative importance weight of the innovation strategy.

The results obtained by using the ANP model indicate that the innovation-based differentiation dominates (weighting = 0.5487 ) other strategies, such as marketing-based differentiation $(0.188)$ and response-time-based differentiation (0.0667). The best choice for the e-business strategist/decision is to select the alternative with the largest desirability index over alternatives with smaller weights. The total number of alternatives can vary by type of industry, type of product/service, size of business, and/or competitive priorities. The choice of the best alternative that evaluates the business-level strategy with dependence and feedback to the desired level of implementation in the four domains of e-commerce strategy (i.e., VIS, VCS, VDS, and VTS) leads to the optimal e-business decision. The findings are discussed in the following section.

\section{RESULTS AND DISCUSSION}

\section{A. Respondent Profile}

Two follow-up electronic mailings/phone calls were made approximately two and four weeks after the date of initial electronic mailings/mailings. The results are summarized in Table VIII.

Possible nonresponse bias was evaluated for all responding firms by using Dun's Regional Business Directory [11] and the Internet Commerce Directory [20]. Comparisons (using chisquare tests) between respondents and non-respondents were made for each industry. No significant relationships were found, thus indicating no apparent industry specific nonresponse bias. As a further test for nonresponse bias, the surveys received were grouped into two "waves" based on the date returned, with later respondents serving as a surrogate for nonrespondents [3]. The first wave included those surveys received within two weeks of the initial mail/e-mail (i.e., before the follow-up e-mail/phonecalls could have been received and acted on) and the second wave included those received after the follow-up by e-mail/phonecalls made about two and four weeks from the date of the initial 
TABLE VII

DESIRABILITy INDEX OF THE THREE DifFERENTIATION STRATEGIES

\begin{tabular}{|c|c|c|c|c|c|c|c|c|c|}
\hline $\begin{array}{l}\text { E- } \\
\text { Commerce } \\
\text { Strategies }\end{array}$ & Weight & $\begin{array}{l}\text { Business } \\
\text { Level } \\
\text { Strategy }\end{array}$ & Weight & $\begin{array}{l}\text { Innovation } \\
\text { Weight }\end{array}$ & $\begin{array}{l}\text { Innovation } \\
\text { Score. }\end{array}$ & $\begin{array}{l}\text { Marketing } \\
\text { Weight }\end{array}$ & $\begin{array}{l}\text { Marketing } \\
\text { Score }\end{array}$ & $\begin{array}{l}\text { Response } \\
\text { Time } \\
\text { Weight }\end{array}$ & $\begin{array}{l}\text { Response } \\
\text { Score }\end{array}$ \\
\hline \multirow[t]{2}{*}{$\begin{array}{l}\text { Virtual } \\
\text { Information } \\
\text { Space }\end{array}$} & 0.561 & $\begin{array}{l}\text { Low Cost } \\
\text { Leader }\end{array}$ & 0.554 & 0.683 & 0.2123 & 0.234 & 0.0727 & 0.083 & 0.0258 \\
\hline & 0.561 & $\begin{array}{l}\text { Unique } \\
\text { Provider }\end{array}$ & 0.563 & 0.683 & 0.2157 & 0.234 & $\begin{array}{l}0.0739 \\
\end{array}$ & 0.083 & 0.0262 \\
\hline \multirow[t]{2}{*}{\begin{tabular}{|l|} 
Virtual \\
Communicat \\
ion \\
Space \\
\end{tabular}} & 0.265 & $\begin{array}{l}\text { Low Cost } \\
\text { Leader }\end{array}$ & 0.273 & 0.683 & 0.0494 & 0.234 & 0.0169 & 0.083 & 0.006 \\
\hline & 0.265 & $\begin{array}{l}\text { Unique } \\
\text { Provider }\end{array}$ & 0.263 & 0.683 & 0.0476 & 0.234 & 0.0163 & 0.083 & 0.0058 \\
\hline \multirow[t]{2}{*}{\begin{tabular}{|l|} 
Virtual \\
Distribution \\
Space \\
\end{tabular}} & 0.122 & $\begin{array}{l}\text { Low Cost } \\
\text { Leader }\end{array}$ & 0.118 & 0.683 & 0.0098 & 0.234 & 0.0034 & 0.083 & 0.0012 \\
\hline & 0.122 & $\begin{array}{l}\text { Unique } \\
\text { Provider }\end{array}$ & 0.123 & 0.683 & 0.0102 & 0.234 & 0.0035 & 0.083 & 0.0012 \\
\hline \multirow[t]{3}{*}{\begin{tabular}{|l|} 
Virtual \\
Transaction \\
Space \\
\end{tabular}} & 0.051 & $\begin{array}{l}\text { Low Cost } \\
\text { Leader }\end{array}$ & 0.054 & 0.683 & 0.0019 & 0.234 & 0.0006 & 0.083 & 0.0002 \\
\hline & 0.051 & \begin{tabular}{|l} 
Unique \\
Provider
\end{tabular} & 0.05 & 0.683 & 0.0017 & 0.234 & 0.0006 & 0.083 & 0.0002 \\
\hline & & & & & 0.5487 & & 0.188 & & 0.0667 \\
\hline
\end{tabular}

TABLE VIII

RESULTS OF SOLICITATION

Declined to participate, citing one or more of the following

reasons:

- Lack of time

- Did not have an e-commerce strategy

- Company policy is not to respond to questionnaires

- Company was currently undergoing restructuring

Responded, but response not usable (either incomplete or had more than one response on questions where only one response was requested)

Responded, response usable (final sample)

- On website (coded as dummy variable 1)

- On hard copy questionnaire (coded as dummy variable 0 )

mail/e-mail. Using this approach, it was possible to determine whether the later respondents differed significantly from earlier respondents on such demographic variables as experience, industry category, and the respondent's number of levels from the CEO of the organization. Using nonparametric statistical tests (e.g., Mann-Whitney and Kruskal-Wallis), there was no discernible difference between the two waves on any of the aforementioned variables. While the earlier tests cannot guarantee the absence of nonresponse bias, the results suggest that the respondents are representative of the population surveyed.

Approximately $39 \%$ of respondents indicated "other" as their organization type. This reporting suggests that future research questionnaires should have additional categories for organization type that accommodate horizontal, vertical, and hybrid (i.e., "clicks and mortar") organizations, such as professional services, utilities, and health care among others.

Approximately $60 \%$ of respondents were IS executives and $40 \%$ were non-IS business executives. This result indicated a good mix of individuals who are qualified to respond to ques-
TABLE IX

EXECUTIVE LEVEL OF RESPONDENTS

\begin{tabular}{||l|l||}
\hline \hline CEO & $6 \%$ \\
\hline One level below the CEO & $27 \%$ \\
\hline Two levels below the CEO & $37 \%$ \\
\hline Three levels below the CEO & $30 \%$ \\
\hline
\end{tabular}

tions concerning e-commerce level strategy and business-level strategy. Job titles consistent with business planners and IS executives confirmed that approximately $70 \%$ of respondents were at the director level or higher. Titles such as CIO, Executive VP, Senior VP, General Manager, IS Director, Web Administrator, and Senior Manager were reported by respondents who were one level below the CEO. It is conceivable that in a small/startup organization, the General Manager/IS Director/Web Administrator may be one level from the CEO due to a relatively small number of employees in the organization. Table IX summarizes the executive level of the respondents.

The study sample was taken from for-profit enterprises involved in e-business, of which approximately $20 \%$ reported a business-to-consumer/retail model, while $72 \%$ reported a $\mathrm{B} 2 \mathrm{~B}$ model, and $8 \%$ reported an enterprise network (i.e., intranet) model. These findings are consistent with a prediction by Forrester Research that most of the e-business activity in the next five years will be in the B2B domain. While the business-toconsumer sector is projected to grow to only $\$ 108$ billion by 2003 in USA, B2B is projected to reach $\$ 1$ trillion by 2003 in USA. With the addition of non-U.S. Internet commerce, ebusiness is predicted to generate revenue of over $\$ 6.8$ trillion in 2004 [35]. This research also demonstrates that e-business is becoming critical in three interrelated dimensions evaluated in the survey instrument: B2B interactions, business-to-consumer 
TABLE X

CHANGES IN THE ORganizATION STRUCTURE TO ACCOMMODATE e-COMMERCE INITIATIVES

\begin{tabular}{|l|l|}
\hline $\begin{array}{l}\text { Assigned IS with the task of implementing e- } \\
\text { commerce }\end{array}$ & $38.8 \%$ \\
\hline $\begin{array}{l}\text { Created a new organization unit with cross- } \\
\text { functional resources, including marketing and } \\
\text { information systems }\end{array}$ & $30.3 \%$ \\
\hline Creating a temporary e-commerce task force & $16.4 \%$ \\
\hline No change in their organization's structure & $14.5 \%$ \\
\hline
\end{tabular}

interactions, and the internal organizational functioning/Intranet dimension.

ANP was used in this study to enable participants to understand, discuss, and evaluate all paired choices in a structured manner, before identifying and selecting the optimal ebusiness option. For example, organizations in the manufacturing industry included contract manufacturers, such as Solectron and Flextronics that receive outsourced manufacturing contracts from Motorola and Cisco among other companies. The reported revenues of randomly selected firms ranged widely from less than $\$ 100$ million to more than $\$ 1$ billion annually. The survey frame consisted of $1250 \mathrm{firms}$, and usable responses were received from 154 firms, representing a $12.32 \%$ overall response rate.

It is interesting to note that about half of the respondents reported that their e-commerce group (which was defined in the cover letter sent with the questionnaire, as the task force/new organization that includes cross-functional resources/individuals from one or more than one department that were responsible for e-commerce initiatives within their organization) was funded independently and empowered locally to make e-business decisions. Another aspect of the study explored changes in organizational structure to accommodate e-commerce initiatives, as illustrated in Table X.

From a strategic management perspective, it is important that the e-commerce group maintains strong linkages with other corporate functions and manages intermediaries involved in the transaction/communication.

The main intent of organizational e-commerce endeavors reported by respondents is shown in Table XI.

More than a third of respondents reported that the results that their company had been able to measure include steadily increasing traffic on company websites, higher percentage of business partners online, more satisfied customers, sales leads, streamlined business processes, and better collaboration with business partners. Higher revenue, higher profits, lower costs, and increased market share were not reported by respondents, indicating that the respondent's organization's had not been able to measure these results. These factors suggest that, although financial return is considered to be the best metric for measuring results, service quality and customer satisfaction are important intangible measures. Customer service ranks among the top objectives of companies implementing e-commerce, where demographic profiles of customers are captured and account information is analyzed. Toyota, for example, uses an Intranet to help sales personnel gain access to data that
TABLE XI

MAIN INTENT OF THEIR ORGANIZATION'S e-COMMERCE ENDEAVOR

\begin{tabular}{|l|c||}
\hline $\begin{array}{l}\text { Transaction processing with electronic } \\
\text { payment }\end{array}$ & $38.3 \%$ \\
\hline Information distribution & $20.1 \%$ \\
\hline $\begin{array}{l}\text { Customer self-service (i.e., order status, } \\
\text { problem resolution, etc.) }\end{array}$ & $18.8 \%$ \\
\hline $\begin{array}{l}\text { Coordination with business partners such as } \\
\text { inventory management }\end{array}$ & $17.2 \%$ \\
\hline $\begin{array}{l}\text { Coordination with business partners such as } \\
\text { sharing data }\end{array}$ & $16.8 \%$ \\
\hline Billing and/or collection services & $14.6 \%$ \\
\hline $\begin{array}{l}\text { Transaction processing without electronic } \\
\text { payment }\end{array}$ & $6.2 \%$ \\
\hline \multicolumn{2}{|l||}{ (The total exceeds $100 \%$, as some respondents checked multiple categories) } \\
\hline
\end{tabular}

TABLE XII

ORGANIZATIONAL COMMITMENT TO e-COMMERCE

\begin{tabular}{||l|l||}
\hline Report hard proof* that e-commerce "works" & $50 \%$ \\
\hline $\begin{array}{l}\text { Believe that e-commerce can make them more } \\
\text { competitive, but waiting for hard proof }\end{array}$ & $38 \%$ \\
\hline Still in development and unsure if there is a payoff & $12 \%$ \\
\hline
\end{tabular}

* hard proof refers to tangible evidence of e-commerce benefits that may directly/indirectly impact the bottom line of the organization.

TABLE XIII

ACTIONS BY ORGANIZATIONS TO PREPARE FOR e-COMMERCE

\begin{tabular}{||l|l||}
\hline $\begin{array}{l}\text { Are training IS and other departments on Internet } \\
\text { concepts and technologies }\end{array}$ & $48 \%$ \\
\hline $\begin{array}{l}\text { Have created several new technical and non-technical } \\
\text { jobs for e-commerce content management and creative } \\
\text { development }\end{array}$ & $25 \%$ \\
\hline Have hired a number of new e-commerce specialists & $15 \%$ \\
\hline Have outsourced e-commerce work & $12 \%$ \\
\hline
\end{tabular}

track the purchasing habits of new car buyers. The National Endowment for AIDS Research employs an extranet to support a virtual organization by having one full-time employee that works with 45 "virtual" volunteers to do all organization fund raising. Tables XII and XIII list organizational commitment to e-commerce and its actions to prepare for e-commerce, respectively, which serve as measures of organizational efforts to prepare for e-commerce initiatives.

Rapidly changing markets in many industries require techniques that expedite decision making, but this shift tends to make the managerial tasks of forecasting, planning, and organization rushed and erratic. Fast-cycle decision making is not just about making decisions more quickly - it is a rethinking of the decision-making model, where managerial intuition, such as the strategic weights placed by decision makers in ANP when making the paired comparisons, replaces extensive analysis as the main driver of decisions. Today's wired world is well suited to fast-cycle decision making, since time is saved by linking many managers to each other by using e-mail, the Internet, and information-sharing software to merge their knowledge bases. The methodology demonstrated in this study can improve a manager's ability to act more quickly and wisely. 
This study found that interactive applications, particularly those that streamline the supply chain through database access and inventory management, are found in the second, third, and fourth phases of implementation (i.e., VCS, VDS, VTS, respectively), and are reported as producing a greater number of results (such as increased market share, higher revenue, more satisfied customers) than do applications in the first phase of implementation that merely publishes information (VIS). The study also found that support from top management team is critical to the success of an e-business strategy. This support was demonstrated in its strongest form by the creation of a new organization design that included cross-functional resources to accommodate e-business initiatives. The value of e-commerce remains difficult to quantify, as explained by one respondent on a follow-up interview who stated that, "although e-commerce has cut paper costs and the Intranet has reduced the volume of e-mail traffic, the percentage of ROI is a nonissue. Rather, the view is that e-business is either helping their firm or it isn't. The outcome is viewed as an attribute and not as a measured value." One CIO reported that the results he has been able to measure from the Web and related technologies have not only been more profitable business opportunities for his company, but e-commerce has also created more job opportunities for CIOs and other IS executives who are being targeted by small Internet startup companies to become CEOs of these e-commerce companies. Finally, revenue generation estimates are largely subjective projections for e-commerce applications that have not yet earned a profit. With costs, value and applications being so variable, comparing the relative merits of projects can become extremely difficult.

\section{B. Limitations of the Study}

Before discussing the implications of this study, it is appropriate to mention its limitations. First, this study relied on selfreported information concerning paired comparisons related to business and e-commerce strategy, and there were no intra- or interconsistency tests. These factors raise the prospect of a possible subjective bias. Second, this study was conducted as a cross-sectional design. A longitudinal study may show different results as the decision maker's criteria and priorities may change over a period of time. Thus, our conclusions must be interpreted with some caution.

The ability to generalize study findings across geographical and organizational boundaries is limited by the composition of the study sample. Also, this study focused on a selected subset of qualitative and quantitative factors in lieu of an exhaustive list, because it was simpler for respondents to complete and return the survey questionnaires in a short period of time. Of course, optimal decisions are contextual based on a particular organization. Finally, the physical aspect/logistics of order delivery and order fulfillment of nondigitizable products were beyond the scope of this research.

\section{Implications for Practice}

The comprehensive strategic justification methodology used in this research can be of significant value to decision makers when applied to technologies whose acquisition can have strategic implications for the enterprise. This methodology can help managers evaluate the strategic value of each virtual space benefit of e-commerce for their organization. More important, participation by employees, customers, and suppliers in this collaborative process is vital to the success of every e-business. As demonstrated in this research, the actual process of deciding on e-business model includes using heuristics. The results of this study can help managers to recognize that, in general, a low-cost leadership business level strategy is preferred over the differentiation strategy in all four domains of e-commerce strategy. Also, innovation-based differentiation is more important when considering the optimal e-business decision than are marketing-based differentiation and response-time-based differentiation.

The conceptualization of the four virtual phases of ecommerce (Fig. 2) and interdependence with business-level strategy (Fig. 3) can be used by managers as a communication tool to better understand and promote consensus regarding the appropriate role of e-commerce in their firms. It is important to be mindful that, in reality, all e-business decisions are based on expectations and subjective projections. For example, such success depends on factors such as the ability of the company to acquire target market in the future, size of the market in the future, future cost to acquire a customer, future cost to support a customer, future value of revenue from a new customer, and future value of a repeat customer. Therefore, any assessment and valuation model will inevitably include subjective components. Nonetheless, it is critical to that decisions be made with the best available data and judgment, for survival into the next generation of e-business will always involve some degree of risk and uncertainty.

\section{Implications for Future Research}

This cross-sectional survey research provides a snapshot of practices or views, at a point in time, from which inferences can be made about extant relationships. While this research methodology enables the description of real-world situations in the e-business domain, more variables and alternatives remain to be studied for making valid generalizations. Since, good measures of qualitative and/or intangible benefits can take years to develop, future research may adapt/extend the ANP model used in this research to address new and better questions related to issues such as improving performance in customer acquisition costs or customer retention efforts, and thereby, increase value postacquisition. The results of this study can enhance the understanding of the relationship between the benefits organizations seek to gain from incorporating information technology capabilities into strategic decisions. ANP methodology can be used to explore the right mix of e-business and traditional business methods and/or the right mix of skills in the organization that would be needed to capitalize on e-business.

Since business models and strategies in e-business are either evolving ad hoc or are being refined by planned innovation, the use of ANP in a longitudinal study could be explored to capture decision-making complexity more completely. ANP can also be employed to help identify disconnects or incompleteness of information exchange between e-commerce technology specialists and business strategists. 
Future research could compare alternative e-business decision modeling techniques, such as process tracing analysis versus ANP to evaluate the effectiveness of the two methodologies and validate the results. As a weighted additive linear modeling technique, ANP focuses on statistical techniques to identify underlying functional relationships, while process tracing focuses on the cognitive processes that underlie judgments. Our literature search did not produce any prior published research that compared a compositional technique, such as AHP or ANP, with process tracing methods.

Finally, although this research focuses on the organization level and encompassed all e-commerce technologies in addition to electronic data interchange (EDI), future studies can add new perspectives when conducted from different levels of analysis. For example, the levels of analysis for the scope of assessments of EDI investments identified by Kambil [21] are the single organization, the dyad (the supplier-buyer relationship), and the network. Two additional levels of analysis, suggested by Hoogeweegen and Wagenaar [18], are the supply-chain level and the industry-segment level. This may help bridge the gap between the theory and practice of e-business.

\section{CONCLUSION}

As industries are reshaped and the nature of competition changes, deciding on an e-business model and strategy to act upon it is a vital starting point for firms that recognize the need to rethink the strategic fundamentals of their business. The major conclusions of the study are that: 1) product differentiation is preferred as a strategy by managers over cost leadership and 2) among differentiation strategies, innovation-based differentiation is preferred over marketing and time-based differentiation. This study shows how to integrate diverse, yet complementary, literature streams to conceptualize a process for e-commerce decision-making. Given the complexity inherent in making the optimal e-business decision, the study analyzes decision rules employed by executive decision makers to determine the optimal mix of technology and strategy for making e-business investments. Numerous strategies and options are available to a decision maker, and the optimal e-business decision may change as the internal and external environments of an organization change.

The results highlight optimal e-business decision making using ANP methodology for unstructured problems that incorporate interrelated technology and business factors/attributes. Since e-business strategy selection is an infrastructure issue and not a technological problem, business design should be used as the starting point for reexamining the fundamental assumptions of how to do businesses. This concept is implicit in the ANP model. Organizations must rethink internal business processes, how customers are approached, and the development of a corporate culture that embraces the Internet. The unique value proposition of an e-business is embedded in the speed and agility gained by establishing a business model that leverages its existing asset base with an integrated approach to business and technology decisions.
Finally, and perhaps most importantly, this study suggests that strategic decision-making research should be expanded to provide a more incisive examination of individual judgments of strategic decision makers. Descriptive research that examines processes, outcomes, and the results of other studies that have addressed process-outcome and outcome-performance relationships have advanced general understanding of strategic decision making. However, executive decision-making focused on the integration of business strategy with the capabilities of e-commerce technologies remains, although relatively unexplored, the essence and determinant of the future of e-commerce deployment and use.

\section{POSTSCRIPT TO AdDRESS THE ISSUE OF IMPLICATION OF THE DOT COM Bust PHENOMENON ON THE FINDINGS}

The growth rate of business investment in IT boomed in the 1990s and 2000 before plunging in 2001. In the years 2000 and 2001, more than 1000 Internet-based firms went out of business worldwide [47]. Consistent with the management literature on organizational failure, factors that contributed to the collapse of dot.com firms were either internal (e.g., poor strategic planning, inexperienced management, inactive board of directors) or external (e.g., lack of available resources and marketplace competition) [41]. The bubble burst just because their share prices had been bid up to irrational and unsustainable levels. Spending $\$ 2.2$ million dollars (or $25 \%$ of Epidemic.com's venture capital spending) on one $30 \mathrm{~s}$ television advertisement during the Super Bowl may create brand recognition, but it does not ensure that paying customers will visit a company's site, especially since long-term loyal customers come to a Web site from affiliate links, search engines, or personal recommendations. Going public before a company has a sound underlying cost and revenue model or relying on venture capitalists to assist a firm strapped for cash is irresponsible and unfair to investors. Surveying the wreckage of the dot-com marketplace meltdown of 2001, it is easy to overlook the persistence and rapid growth of e-business throughout the U.S. economy. While many dot-com firms, including Beyond.com, Boo.com, DrKoop.com, eRegister.com, Garden.com, Furniture.com, Kozmo.com, Pets.com, and Webvan failed, the use of the Internet as an essential business tool continued to grow dramatically. Today, legacy firms represent the future of e-business and understanding e-business from their perspective gives a clearer picture of how e-business will develop in the future. The online grocers represent a clear example. The pure-plays Homegrocer and Webvan received enormous media attention and heavy investment from venture capitalists. Today, both are out of business, while traditional British grocer Tesco has emerged as the most successful grocer online [33].

Companies must now rediscover the principles that governed businesses prior to the e-commerce era [24]. This boom and bust raises some natural questions: what were the reasons for the accentuated swings in growth rates, and, more importantly, what do those reasons portend for the future of IT investment? Much of the increase in IT investment in the late 1990s appears to be attributable to falling prices of IT goods, which, in turn, is largely attributable to technological change. However, 
IT investment was much higher in 1999 and 2000 than a model would predict. Another reason for the high growth rates in IT investment was that expectations were too high, especially in two sectors of the economy, telecommunications services and the dot-com sector [12]. Dot-coms must be rebuilt and transformed to face the new economy: not only must they devise innovative e-strategies, but they must also restructure around new business models.

From 2000 to 2002, painful as failures are, at least they can point out some valuable lessons to the e-business companies, and let them know that they need new strategies to do business. Zhang and Gai [50] explored the essence of e-business strategy and found that e-business offers important advantages over its predecessor, and the Internet enables the integration of the value chain and entire value systems. Aligning value drivers such as revenue, cost, customer service, time to market, agility, fulfillment time, and market reach to achieve competitive advantage could serve as the analytical framework for e-business.

With respect to perceived importance of e-strategies, Lai and Wong [24] found that, in the post dot com bust era, the most important was a policy-related strategy adopted by both e-commerce and non-e-commerce companies to streamline and rebuild a robust Internet business model. This finding is not surprising, as many e-commerce companies had been criticized for having business plans that were too aggressive, with too much emphasis on market capitalization. The higher survival rate of B2B companies, as compared to B2C companies, has provided solid evidence for the significance of a good business model. In the heyday of e-commerce, most B2C companies were new and lacked profit foundations. Also, customers were unfamiliar with these models, and hence, had unclear expectation levels. Although the strategy to rebuild a robust Internet business model has not been as widely implemented as had been anticipated, it has had a significant influence on company performance.

To determine the effectiveness of all e-strategies, data on the extent of their implementation was regressed with e-commerce company performance data for a correlation analysis. Only six e-strategies-spending control, trusted infrastructure establishment, B2B evolution, business model selection, growth control, and strategic alliances-were significant. It is interesting to note that of the six performance-contributing estrategies, all savings-related e-strategies were critical. During the e-commerce heyday, most e-commerce companies were condemned for being too hasty and for expanding too rapidly, which resulted in capacity and resources being stretched to the limit. Such uncontrolled and unplanned expansion sped up burn rates, which eventually put many e-commerce companies out of business. Hence, the control of such spending and growth will improve e-commerce performance.

Electronic business should be part of the overall corporate strategy and be integrated into core business processes. Hooshang et al., [19] found that dissatisfaction with e-business could stem from problems in one or more of the following areas:

1) planning and design of e-business model;

2) hardware and software security;

3) integration of e-business applications with internal information systems and business partners;
4) telecommunications network and protocols;

5) Web page design and navigation.

Although the strategy to rebuild a robust Internet business model has not been as widely implemented as had been anticipated, it has had a significant influence on company performance. For companies that have replaced their speculative business models with models that are clearly expressed in terms of direction and revenue (e.g., to a more reliable B2B domain), their financial performances have subsequently improved. Lai and Wong performed a moderated regression analysis to evaluate the moderating effect of business type on strategy-performance relationship, and found that the business type has a significant moderating effect on e-strategy for company performance, which means that there must be a fit between business type and e-strategy type for a company to optimize its performance [24]. The Pearson correlation analysis performed by Lai and Wong found that strategies affected e-commerce companies more significantly than non-e-commerce companies [24]. Of the two e-commerce business types, B2B companies benefited from all, but the marketing-related e-strategies that specified offline strength and evolution to the $\mathrm{B} 2 \mathrm{~B}$ domain were inapplicable to these B2B companies. Besides many B2B companies in Hong Kong provide general services to set up e-commerce infrastructure and maintain Web sites for other companies, and are still far from building their brand names and/or finding their market niches. B2C companies, in contrast, could only benefit from cost-savings-related strategies since the burst of the dotcom bubble forced B2C companies to focus more on savingsrelated issues, thus giving rise to the influence of savings-related e-strategies on performance. Further, Lai and Wong's statistical evaluation suggested that savings-related strategies were the most effective for the B2B and B2C companies, whereas marketing-related strategies were only effective for the non-ecommerce companies [24].

Finally, the value of e-commerce strategy is also found in Thompson et al.,'s study that derived a comprehensive list of inhibitors from an extensive review of the literature, pretested with senior IT executives, and analyzed data from 249 firms using factor analysis to yield the underlying structural dimensions of inhibitors impacting the deployment of Web-based B2B ecommerce [46]. The results suggest that key inhibitors in B2B deployment are the lack of top management support, unresolved technical issues, the lack of e-commerce strategy, and the difficulties in cost-benefit assessment of e-commerce investments. Now, we need to focus on what does work so that we can help managers build stronger companies in the future using information and knowledge as the currency of e-business as much as or more than physical assets. Strategies such as channel enhancement, value chain integration, industry transformation, convergence, and their impact on organizations, people, process, and technology can be assessed and evaluated using the ANP model presented in this paper to think about ongoing e-business value to the organization beyond traditional organizational boundaries.

\section{ACKNOWLEDGMENT}

The authors would like to thank the Editor-in-Chief, Dr. G. Farris, the Associate Editor, Dr. A. Chakrabarti, and the anony- 
mous reviewers for their constructive comments, who helped in enhancing the quality of this manuscript.

\section{REFERENCES}

[1] A. Angehrn, "Designing mature internet strategies," Eur. Manage. J., vol. 154 , pp. 361-369, 1997.

[2] A. Angehrn and J. Meyer, "Developing mature Internet strategiesInsights from the banking sector," Inf. Syst. Manage., vol. 14, pp. 37-43, 1997.

[3] E. R. Babbie, Survey Research Methods. Belmont, CA: Wadsworth, 1973.

[4] J. F. Bard and S. F. Sousk, "A tradeoff analysis for rough terrain cargo handlers using the AHP: An example of group decision-making," IEEE Trans. Eng. Manage, vol. 37, no. 3, pp. 222-227, Aug. 1990.

[5] E. Brynjolfsson and L. Hitt, "Evidence on the returns to information systems spending," Manag. Sci., vol. 42, pp. 541-558, Apr. 1996.

[6] E. Brynjolfsson and L. Hitt, "Beyond the productivity paradox," Commun. ACM, vol. 41, pp. 49-55, Aug. 1998

[7] J. Child, "Strategies of control and organizational behavior," Admin. Sci. Quart., vol. 18, pp. 1-17, 1973.

[8] The Organization for Electronic Commerce Member Directory. Dallas/Fort Worth EDI Forum, Arlington, TX, 1997.

[9] G. G. Dess and P. Davis, "Porter's generic strategies as determinants of strategic group membership and organizational performance," Acad. Manag. J., vol. 27, pp. 467-488, 1984.

[10] G. G. Dess and A. Miller, Strategic Management. New York: McGrawHill, 1993.

[11] Dun's Regional Business Directory. Dallas/Fort Worth Region, TX, vol. 3, 1997, pp. 1198-1199.

[12] M. Doms, "The boom and bust in information technology investment," Fed. Reserve Bank San Francisco Econ. Rev., pp. 19-35, 2004.

[13] R. F. Dyer and E. H. Forman, "Group decision support with the analytic hierarchy process," Decis. Supp. Syst., vol. 8, pp. 99-124, 1992

[14] V. Grover. (1997). A tutorial on survey research: From constructs to theory [Online]. pp. 1-15. Available: http://theweb.badm.sc.edu/ grover/survey/MIS-SUVY

[15] R. Gulati and J. Garino, "Get the right mix of bricks and clicks," Harv. Bus. Rev., pp. 112-120, May-Jun. 2000.

[16] D. C. Hambrick, "An empirical typology of mature industrial product environments," Acad. Manag. J., vol. 26, pp. 213-230, 1983.

[17] D. C. Hambrick, "High profit strategies in mature capital goods industries: A contingency approach," Acad. Manage. J., vol. 26, pp. 687-707, 1983.

[18] M. R. Hoogeweegan and R. W. Wagenaar, "A method to assess expected net benefits of EDI investments," Int. J. Eletron. Commerce, vol. 11, pp. 73-94, 1996.

[19] M. B. Hooshang, E. Salehi-Sangari, and A. Engstrom, "Competitive advantage with e-Business: A survey of large American and Swedish firms," Compet. Rev., vol. 16, pp. 150-167, Feb. 2006.

[20] Internet Commerce Directory. Gateway Publishing, North Adams, MA, 1997.

[21] A. Kambil, "Electronic integration: A critical review and network extensions," in Scientific Research on EDI "Bringing Worlds Together," R. J. Streng, C. F. Ekering, E. van Heck, and J. F. H. Schultz, Eds Alphen Aan de Ryn, The Netherlands: Samson, 1992, pp. 209-231.

[22] J. Kim, "A survey study on the relative importance of intranet functions: Using the analytic hierarchy process," presented at the 1997 Int. Decus. Sci. Inst. Meeting, Sydney, Australia, Jul. 1997.

[23] N. K. Kwak and C. Lee, "A multicriteria decision-making approach to university resource allocations and information infrastructure planning," Eur. J. Oper. Res., vol. 16, pp. 234-242, Oct. 1998.

[24] V. S. Lai and B. K. Wong, "Business types, e-strategies, and performance," Commun. ACM, vol. 48, May 2005.

[25] I. C. MacMillan and D. Hambrick, "Capital intensity, market share instability and profits-the case for asset parsimony," Columbia Univ. Strat. Res. Center, New York, 1983.

[26] L. Meade and A. Presley, "R\&D project selection using the analytic network process," IEEE Trans. Eng. Manag, vol. 49, no. 1, pp. 59-67, Feb. 2002

[27] L. Meade and J. Sarkis, "Strategic analysis of logistics and supply chain management systems using the analytical network process," Transp. Rev. E, Log. Transp. Rev., vol. 34, pp. 201-215, Sep. 1998.

[28] L. Meade, "An application of ANP to strategic analysis of modern logistics systems," in Proc. Int. Symp. Anal. Heirarchy Process, Vancouver, BC, Canada, vol. 12-15, Jul. 1996, pp. 82-93.
[29] R. Miles and C. Snow, Organizational Strategy, Structure and Process. New York: McGraw-Hill, 1978.

[30] D. Miller and P. H. Friesen, Organizations: A Quantum View. Englewood Cliffs, NJ: Prentice-Hall, 1984.

[31] D. Miller, "Configurations of strategy and structure: Towards a synthesis," Strat. Manag. J., vol. 7, pp. 233-249, 1986.

[32] J. C. Nunnally, Psychometric Theory. New York: McGraw Hill, 1978.

[33] E. J. Pinker, A. Seidmann, and R. C. Foster, "Strategies for transitioning old economy firms to e-business," Commun. ACM, vol. 45, no. 5, pp. 7783, 2002.

[34] M. Porter, Competitive Strategy. New York: Free Press, 1980.

[35] R. W. Price, Annual Editions: E-Business 01/02. Guilford, CT: McGraw-Hill/Dushkin, 2001.

[36] M. S. Raisinghani and L. L. Schkade, "An analytic tool for strategic evaluation of advanced networking technologies," presented at the 1997 Int. Decis. Sci. Inst. Meeting, Sydney, Australia, Jul. 1997.

[37] M. S. Raisinghani, "Internet-Intranet empowered global organizations: Planning and strategic implications," presented at the 1997 Assoc. Inf. Syst. Annu. Meeting, Global Inf. Technol. Track, Indianapolis, IN, Aug 1997.

[38] M. S. Raisinghani, "Strategic evaluation of e-commerce technologies: An application of the analytic hierarchy process," presented at the 1997 Assoc. Inf. Syst. Annu. Meeting, Research-in-progress Minitrack, Indianapolis, IN, Aug. 1997.

[39] B. H. Reich, "Investigating the linkage between business and information technology objectives: A multiple case study in the insurance industry," Ph.D. dissertation, Univ. British Columbia, Vancouver, BC, Canada, 1993.

[40] B. H. Reich and I. Benbasat, "Measuring the linkage between business and information technology objectives," MIS $Q$., vol. 20, pp. 55-77, Mar. 1996.

[41] J. Rovenpor, "Explaining the e-commerce shakeout: Why did so many Internet-based businesses fail?," E-Service J., vol. 3, pp. 53-77, Jan. 2003.

[42] R. P. Rumelt, Strategy, Structure, and Economic Performance. Cambridge, MA: Harvard Graduate School of Business Administration, 1974.

[43] T. L. Saaty, Multicriteria Decision Making: The Analytical Hierarchy Process. Pittsburg, PA: RSW Publications, 1988.

[44] T. L. Saaty, Analytic Network Process. Pittsburg, PA: RWS Publications, 1996.

[45] F. Scherer, Industrial Market Structure and Economic Performance. Chicago, IL: Rand McNally, 1980.

[46] T. S. Thompson, C. Ranganathan, and J. Dhaliwal, "Key dimensions of inhibitors for the deployment of Web-based business-to-business electronic commerce," IEEE Trans. Eng. Manag., vol. 53, no. 3, pp. 395-411, Aug. 2006.

[47] E. Turban, D. King, D. Viehland, and J. Lee, Electonic Commerce: A Managerial Perspective. Upper Saddle River, NJ: Pearson/Prentice-Hall, 2006.

[48] A. H. Van de Ven and R. Drazin, "The concept of fit in contingency theory," Res. Org. Behav., vol. 17, pp. 333-365, 1985.

[49] B. Violino, "ROI: The intangible benefits of technology are emerging as the most important of all," Inf. Week, vol. 30, pp. 36-44, Jun. 1997.

[50] G. Zhang and G. Jianhua, "E-commerce-models, structure, mechanisms, globalization, and strategy: Strategic choice for being e-business," in Proc. 7th Int. Conf. Electron. Commerce, Aug. 2005, pp. 184-187.

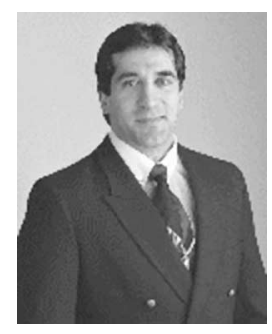

Mahesh S. Raisinghani received the M.S. and Ph.D. degrees from the University of Texas, Arlington.

He is currently an Associate Professor in the Executive M.B.A. program, School of Management, Texas Woman's University, Denton. He is also a certified e-Commerce Consultant and a Project Management Professional. He has authored or coauthored several papers published in various journals.

Dr. Raisinghani was the recipient of Texas Woman's University School of Management's 2005 Best Professor Award for the most innovative teaching methods, the 1999 University of Dallas Graduate School of Management Presidential Award, the 2001 King/Haggar Award for excellence in teaching, research, and service, and the 2002 Research Award from University of Dallas GSM. 


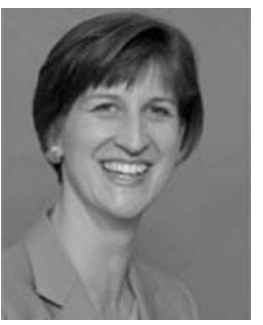

Laura M. Meade received the B.S. degree in mechanical engineering from Valparaiso University, Valparaiso, IN, and the M.B.A. and Ph.D. degrees in industrial engineering from the University of Texas, Arlington.

She is currently an Associate Professor of supply chain practice at Texas Christian University, Fort Worth. She was with the Automation and Robotics Research Institute, University of Texas, Arlington. She has taught supply chain management courses at the undergraduate and graduated levels. She has led several student groups through company-sponsored projects. She has also consulted and taught executive courses for several companies. Her research interests include general dynamics, enterprise modeling, supply chain management, and reverse logistics. She has authored or coauthored several papers published in various journals.

Dr. Meade is a member of the Decision Sciences Institute and the Council of Supply Chain Management.
Lawrence L. Schkade received the Ph.D. degree.

$\mathrm{He}$ is currently a Regents Professor and the Dean of Business Emeritus, University of Texas, Arlington. He has been recognized internationally for research on artificial intelligence, healthcare, information processing, and system theory. He is the author or coauthor of numerous published books and research monographs, and a host of articles published in many refereed journals.

Dr. Schkade is the recipient of many awards, listings, and other recognitions for research, scholarship, and leadership. He is a member of the Families of Adults Afflicted with Asperger's Syndrome and Franchise Development Services International. 